\section{A voz da biologia: ciência e ideário político no Brasil nos anos 1920-1940}

\author{
Por José Luiz de Andrade Franco \\ Universidade de Brasilia \\ (jldafranco@terra.com.br)
}

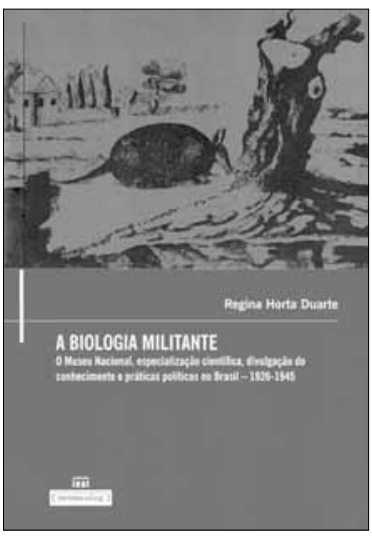

DUARTE, Regina Horta. A Biologia Militante: o

Museu Nacional, especialização científica, divulgação do conhecimento e práticas políticas no Brasil - 1926-1946.

Belo Horizonte: Editora UFMG, 2010. 219 p. ISBN 978-857041-860-9

O livro "A Biologia Militante: o Museu Nacional, especialização científica, divulgação do conhecimento e práticas políticas no Brasil - 1926-1946", de Regina Horta Duarte, é o resultado de extensa pesquisa - duzentas fontes primárias e ampla bibliografia secundária são citadas - e tem um conteúdo que articula com maestria história da ciência, história intelectual, história política e história das instituições. É também uma lição de como escrever uma narrativa histórica sem incorrer nos 'pecados capitais' denunciados por Marc Bloch: 'a mania de julgar' e a 'procura das origens'. A autora, a partir de questões cuidadosamente elaboradas, desfia as redes que entrelaçavam o conhecimento científico, sobretudo da biologia, com práticas e ideias políticas no Brasil dos anos 1920-1940. O que move a pesquisa é a busca por compreender como a experiência de determinados indivíduos e a participação deles em instituições públicas e privadas da sociedade brasileira foi, ao mesmo tempo, produto e produtora do contexto histórico em que eles viveram, pensaram e agiram.

Duarte é professora titular da Universidade Federal de Minas Gerais (UFMG), posição que alcançou ainda jovem para os padrões da academia. Obteve esse título justamente com a apresentação, como tese defendida em concurso, do texto agora publicado na forma de livro. Trata-se de uma obra madura e bem desenhada, fruto dos investimentos da autora, já de longa data, nas áreas de história das ideias, história das ciências e história ambiental. Este último campo tem recebido uma contribuição bastante grande da autora no que diz respeito à sua institucionalização no Brasil. Ela tem organizado números de revista dedicados ao tema, congressos e seminários, além de ter formado mestres e doutores com atuação na área e articulado redes de contato e circulação de conhecimentos.

A reflexão proposta por Duarte parte da percepção de como, nas décadas de 1920 e 1930, alguns dos membros do Museu Nacional do Rio de Janeiro (MNRJ) se engajaram em uma luta incansável para a recriação desta instituição, repensando o seu papel no cenário nacional e transformando-a em um centro produtor e irradiador de conhecimentos para as mais variadas localidades do Brasil. Inseridos em um amplo debate acerca dos obstáculos para a construção da nação e sobre a formação da identidade nacional, os cientistas do MNRJ apostaram nas mais diversificadas formas de comunicação para atingir a população brasileira, em todas as faixas da sociedade: impressos, rádio, cinema, exposições, palestras e outras ações educativas diretas.

Havia, segundo a autora, uma verdadeira obsessão pedagógica, caracterizada por um voluntarismo, uma visão autoritária do Estado e da sociedade, e uma crença em que medidas adequadas dirigidas à população poderiam trazê-la à cena em sua 'verdade' mais profunda, com base em uma cultura popular domesticada pelo saber erudito e pela ciência, o que resultaria no afloramento da 'genuína' nacionalidade. Além de uma influência forte de pensadores como Alberto Torres, os membros do MNRJ fundamentavam a sua atuação nos conhecimentos proporcionados pela emergência dos saberes biológicos, que desempenharam um papel estratégico na interpretação do Brasil e na formulação de práticas sociais que visavam a sua transformação. 
Duarte focaliza a sua atenção sobre três personagens importantes para o MNRJ e para o desenvolvimento da biologia no Brasil: o zoólogo Cândido de Mello Leitão, o botânico Alberto José de Sampaio e o antropólogo Edgard Roquette-Pinto. Até os marcos cronológicos que definem o escopo temporal da pesquisa foram estabelecidos em função das experiências de vida dessas personagens. $\mathrm{O}$ ano de 1926 foi o do início da gestão de Roquette-Pinto como diretor do MNRJ, e o de 1945, o da última viagem de Mello Leitão como representante cultural do governo brasileiro em missão na América Latina. Para Duarte, a ascensão nacional e internacional de cientistas como Mello Leitão demonstrava uma especialização efetiva da ciência biológica e a constituição de uma "biologia militante" no Brasil, ainda que não houvesse naqueles anos cursos específicos para a formação de biólogos ou um reconhecimento formal da profissão.

O livro se divide em três capítulos: "A voz mais alta da Biologia", "A miniatura da pátria" e "Como se fazia um biólogo". No primeiro, a autora se lança à compreensão das condições históricas que possibilitaram ao MNRJ constituir uma estratégia de revigoramento da sua presença no cenário político nacional e das razões do sucesso de seus cientistas na aproximação com os poderes públicos instituídos durante o Governo Provisório de Getúlio Vargas. Ela mostra como a biologia se constitui como campo específico do conhecimento e se afirma como um saber decisivo na resolução de problemas políticos, sobretudo a partir da emergência da população como objeto de preocupação nacional - vale a pena lembrar que, na medida em que a população do Brasil passava a ser um tema de reflexão, o conceito de população em voga nas ciências biológicas tornava-se instrumental para produzir explicações sobre a sociedade brasileira. As trajetórias de vida de Roquette-Pinto, Mello Leitão e Sampaio são escrutinadas. A emergência deles como autoridades científicas é inserida em uma rede de apoios institucionais e relações pessoais, que acaba por entrelaçar, sobretudo, o MNRJ e o Ministério da Educação e Saúde Pública. As concepções sobre uma natureza harmônica, predominantes no campo da biologia, sintonizavam os cientistas do MNRJ com o ideário político autoritário e corporativista, negador dos conflitos sociais e adepto de uma metáfora orgânica de sociedade, metáfora essa que dava sustentação ao regime de Vargas. A última parte do capítulo trata da participação dos cientistas do MNRJ na elaboração do Código de Caça e Pesca de 1934, com destaque para os seus êxitos e as suas frustrações no que diz respeito ao texto final da Lei.

No segundo capítulo, Duarte mostra como alguns membros do MNRJ se engajaram no jogo político e delinearam as suas ações com o intuito de assumir um papel ativo na educação do 'povo brasileiro'. Ela explora as relações do MNRJ com o Ministério da Educação e Saúde Pública, a utilização de novas tecnologias - sobretudo aquelas relacionadas com a radiodifusão - e a diversidade de linguagens mobilizadas nas iniciativas pedagógicas. Tratase de demonstrar como a atividade dos cientistas do MNRJ estendeu-se para bem além dos muros da instituição.

O terceiro capítulo narra a experiência de Mello Leitão como biólogo. O objetivo é mostrar, a partir de um estudo de caso, "como se fazia um biólogo na interseção de redes relacionais e no devir histórico de práticas diversas". É aqui também que se pode perceber claramente a intenção da autora de refletir sobre as possibilidades de criação e inovação por parte dos atores sociais, na medida em que se envolvem com os problemas e desafios políticos e intelectuais de seu tempo.

$\mathrm{Na}$ conclusão do livro, Duarte reforça o caráter de aventura intelectual da experiência vivida por RoquettePinto, Mello Leitão e Sampaio. Eles foram persistentes e criativos na afirmação de um conhecimento constituído como prática política, interessada e potencialmente transformadora, a "biologia militante". A leitura do texto de Duarte interessa a todos aqueles, acadêmicos ou leigos, que pretendem conhecer melhor as relações entre ciência e ação política no Brasil dos anos 1920-1940. É indispensável para os pesquisadores que se dedicam à compreensão do ideário político da era Vargas. 